\title{
Presyncope Due to a Complete Atrioventricular Block Revealing a Rheumatic Heart Disease
}

\section{Souilmi FZ*, Atmani S, Chaouki S and Hida M}

Faculty of Medicine and Pharmacy, Department of Pediatrics, Hassan II University Hospital of Fez, Sidi Mohamed Ben Abdellah University, Fez, Morocco

\begin{abstract}
First degree Atrio Ventricular (AV) block is a common manifestation of acute Rheumatic Fever (RF) and is included in the Jones criteria but Wenckebacks phenomena and complete heart block are rarely described in the RF. Presyncope occurring in RF was rarely reported. We report the case of a young 14 years old boy with rheumatic heart disease revealed by presyncope due to an third degree AV block. Rapid improvement was obtained under corticosteroids.
\end{abstract}

Keywords: Atrioventricular block; Rheumatic fever

\section{Introduction}

Various rhythm and conduction abnormalities can develop in acute Rheumatic Fever (RF). The most common conduction abnormalities are sinus tachycardia, atrioventricular block (AV) of the first degree with prolongation of the PR interval (greater than $0.16 \mathrm{~s}$ ). The seconddegree Avblock (Luciani-Wenckebach) is also rare and has the same meaning as the PR prolongation. Complete AV block associate or not to Adams-Stokes syndrome is exceptionally found in the acute RF [1]. We report an unusual mode of revelation of acute RF, presyncope secondary to a complete atrioventricular block in an adolescent of 14 years.

\section{Case Report}

A 14 year old boy, weight $42 \mathrm{~kg}$ was admitted to the pediatric emergency room for several episodes of presyncope episodes which occurred 3 days before. He had complained of transient thoracic pain the day before. On admission, the patient appeared pale and asthenic. The axillary temperature was $38.5^{\circ} \mathrm{C}$, the blood pressure (BP) was $100 / 50 \mathrm{mmHg}$, the pulse rate was 46 beats/minute and the respiratory rate was $26 /$ minute. The cardiac examination revealed an irregular rhythm, bradycardia and mild systolic murmur. The findings from pulmonary and abdominal examinations were normal. History pointed out a recurrent anginas untreated or poorly cared. The first ECG recording revealed complete heart block (Figure 1). A chest radiograph showed a normal cardiothoracic ratio.

Laboratory studies showed the following values: white blood cell count, 9,500/ $\mathrm{L}$; hemoglobin, $11.5 \mathrm{~g} / \mathrm{dl}$; erythrocyte sedimentation rate (ESR), $100 \mathrm{~mm} /$ first hour and $150 \mathrm{~mm} / \mathrm{second}$ hour (upper limit of normal $=20 \mathrm{~mm} / \mathrm{hr}$ ), C-reactive protein (CRP) level, $85 \mathrm{mg} / \mathrm{l}$ (upper limit of normal $=6 \mathrm{mg} / \mathrm{l})$; and antistreptolysin O (ASO) titer, $500 \mathrm{IU} /$ $\mathrm{mL}$ (nor $\mathrm{mal}<200 \mathrm{IU} / \mathrm{mL}$ ). Serological tests for Lyme disease, typhoid fever, Epstein Barr virus (EBV), cytomegalovirus (CMV), coxackie virus, chlamydia and mycoplasma were negative.

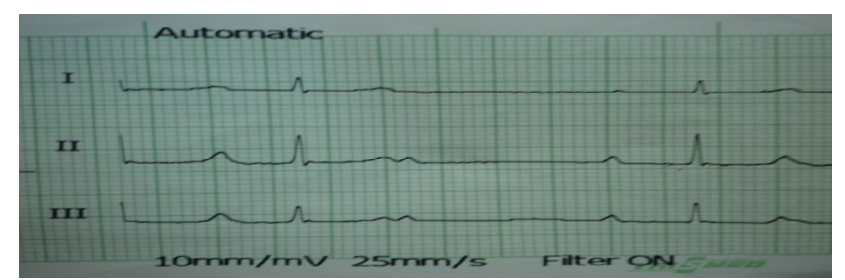

Figure 1: ECGon the first day: AVblocktype III: Heart rate $42 \mathrm{bt} / \mathrm{min}$.
The diagnosis of rheumatic heart disease complicated by complete AV block during a first attack of rheumatic fever was retained according to the criteria of Jones. The patient was treated with corticosteroids (prednisone $2 \mathrm{mg} / \mathrm{kg} /$ day) and amoxicillin. Continuous monitoring of pulse rate, ECG and BP has been established. After 48 hours of treatment there was an improvement with BAV who became the first degree (Figure 2) and thereafter, the ECG became normal (Figure 3). At 15 days, the inflammation decreased (ESR: $07 \mathrm{~mm}$ first hour, $17 \mathrm{~mm}$ in the second hour) and a gradual degression of corticosteroids for 12 weeks was prescribed. Intramuscular injections of benzyl penicillin (1.2 million IU) every 3 weeks were prescribed for secondary prophylaxis.

\section{Discussion}

First-degree heart block is a common electrocardiographic manifestation (72.3\%) of acute rheumatic fever and is included in Jones' diagnostic criteria. According to different studies, rarely, advanced conduction delay, such as $2^{\text {nd }}$-degree or complete block (in respectively $1.5 \%$ and $4.6 \%$ ), or even Adams-Stokes attacks, are signs of $\mathrm{RF}$, and may precede other signs [2-5]. The exact mechanism by which the rheumatic process causes conduction disturbances is unknown [5]. However, their presence in several febrile and inflammatory conditions even in the absence of carditis and especially the rapid improvement of these disorders on anti-inflammatory treatment suggests that they are mostly a witness to an active inflammatory process [5]. It has been suggested that conduction abnormalities are due, in part, to an

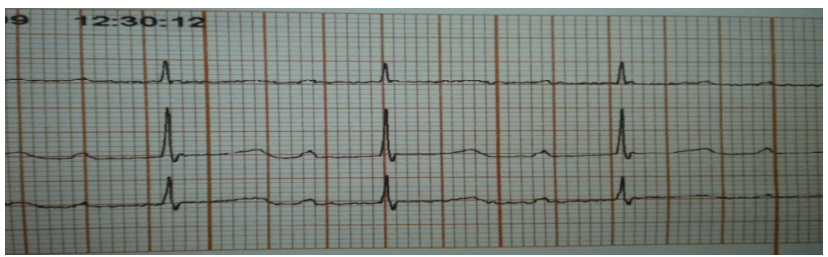

Figure 2: ECG after 48 hours: AV block type I: Prolongation of PR to $0.28 \mathrm{~s}$.

*Corresponding author: Souilmi FZ, Faculty of Medicine and Pharmacy, Sid Mohamed Ben Abdellah University, Fez, Morocco, Tel: +212 661353 669; E-mail: fzsouilmi@gmail.com

Received June 28, 2014; Accepted July 18, 2014; Published July 21, 2014

Citation: Souilmi FZ, Atmani S, Chaouki S, Hida M (2014) Presyncope Due to a Complete Atrioventricular Block Revealing a Rheumatic Heart Disease. J Clin Case Rep 4: 386. doi:10.4172/2165-7920.1000386

Copyright: (c) 2014 Souilmi FZ, et al. This is an open-access article distributed under the terms of the Creative Commons Attribution License, which permits unrestricted use, distribution, and reproduction in any medium, provided the original author and source are credited. 


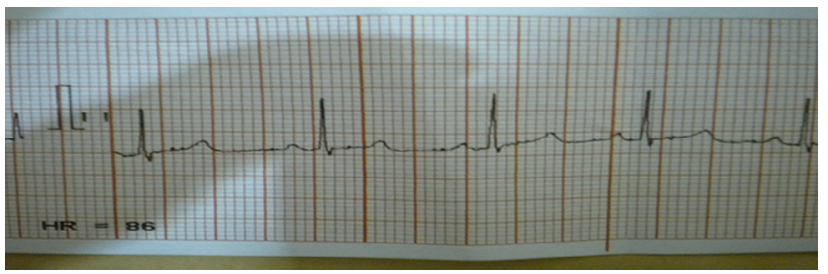

Figure 3: ECG after 15 days: regularsinusal rhythm, PR $0.16 \mathrm{~s}$.

increased vagal tone. The site of vagal hypertonia may be in the vagal center of the medulla, but there is evidence that this excessive nerve endings of heart. Other part, inflammation of the AV node and the His bundle may be the cause of AV block. This data showed that syncope or pre-syncope (probably) can be the first or the most dominant clinical manifestation of ARF [6]. In other systemic inflammatory diseases occurring in the pregnant, eg Systemic lupus erythematous or Sjogren's syndrome, auto-antibodies are responsible for ventricular endocardium damage and subsequent endomyocardial fibroelastosis which can cause fetal third degree AV [7].

According to data from the literature, the AV block can lasted from a few minutes to ten days; in one case, an ECG three months later showed persistence of the complete block [8]. But in general, if complete block occurs with acute RF, it appears to be temporary [4].

Advanced heart block with RF is resolving over a period of days with conventional anti-inflammatory treatment (aspirin or steroids) [5]. The insertion of a temporary pacemaker is necessary in those situations: advanced AV block determines Adams-Stokes attacks or resulted in syncope and in persistant clinical symptoms $[4,8,9]$. In some cases, the AV block can be very transient and reversible without any pharmacological or electrical intervention [2]. Our case illustrates an exceptional mode of revelation of rheumatic heart disease in a patient who was admitted for presyncope episodes due to a complete AV block. The course was rapidly favorable with anti-inflammatory treatment, which is consistent with literature data. After 15 days the ECG was completely normalized in parallel with complete regression of the inflammatory syndrome.

\section{Conclusion}

The third degree AV block is a rare and severe complication of rheumatic fever. If the treatment is appropriate and quickly established the improvement is rapidly obtained. So rheumatic fever must be kept in mind in the diagnostic work-up of paediatric patients with acquired complete AV block especially in the context of presyncope.

\section{References}

1. Barsaoui S, Oubich F (2003) Rheumatic fever in children. Encycl Med Chir Cardiology, 11: 940.

2. Malik JA, Hassan C, Khan GQ (2002) Transient complete heart block complicating acute rheumatic fever. Indian Heart J 54: 91-92.

3. Balli S, Oflaz MB, Kibar AE, Ece I (2013) Rhythm and conduction analysis of patients with acute rheumatic fever. Pediatr Cardiol 34: 383-389.

4. Zalzstein E, Maor R, Zucker N, Katz A (2003) Advanced atrioventricular conduction block in acute rheumatic fever. Cardiol Young 13: 506-508.

5. Yoo GH (2009) Completeatrioventricular block in an adolescent with rheumatic Fever. Korean Circ J 39: 121-123.

6. Duran NE, Sönmez K, Biteker M, Ozkan M (2009) A case of acute rheumatic fever presenting with syncope due to complete atrioventricular block. AnadoluKardiyolDerg 9: 68-69.

7. http://www.embj.org/

8. Carano N, Bo I, Tchana B, Vecchione E, Fantoni S, et al. (2012) Adams-Stokes attack as the first symptom of acute rheumatic fever: report of an adolescent case and review of the literature. Ital J Pediatr 38: 61.

9. Mohindra R, Pannu HS, Mohan B, Kumar N, Dhooria HS, et al. (2004) Syncope in a middle aged male due to acute rheumatic fever. Indian Heart J 56: 668-669. 